\title{
Sistem Absensi Pengenal Wajah Menggunakan Webcam Dengan Library Pada EMGUCV
}

\author{
Tri Cahyadi, Novi Azman, Fuad Djauhari \\ Program Studi Teknik Elektro, Fakultas Teknik dan Sains, Universitas Nasional \\ J1. Sawo Manila, Pejaten, Pasar Minggu, Jakarta 12520 \\ Korespondensi: tricah21@gmail.com
}

\begin{abstract}
ABSTRAK. Absensi adalah salah satu transaksi repetitif yang sangat penting, karena berkaitan dengan produktifitas dari karyawan dan merupakan salah satu indikator pengontrol Sumber daya manusia (SDM) yang bertujuan meningkatkan potensi sumber daya manusia serta digunakan dalam rangka efisiensi. Perkembangan teknologi saat ini memungkinkan membuat suatu sistem yang dapat membantu manusia dalam pengenalan suatu citra digital. Dalam penelitian pengenalan wajah ini menggunakan sebuah kamera untuk menangkap wajah seseorang kemudian dibandingkan dengan wajah yang sebelumnya telah disimpan di dalam database tertentu. Secara garis besar proses dari pengenalan wajah ini adalah kamera webcam melakukan capture pada wajah. Dengan menggunakan pemrosesan awal, dilakukan crop, scaling dan konversi RGB ke grayscale. Setelah dilakukan proses grayscale, dilakukan tahap pengolahan wajah dengan menggunakan metode haar classifier yang terdapat pada library EmguCv.
\end{abstract}

Kata Kunci: Pengenalan Wajah, Data base Absensi, Haar Classifier.

\section{PENDAHULUAN}

Perkembangan teknologi semakin berkembang dengan pesat. Banyak metode yang digunakan untuk mengidentifikasi seseorang. Media yang paling umum dalam metode verifikasi dan identifikasi adalah password, smartcard, dan fingerprint. Tingkat keamanan yang kurang optimal dikarenakan sistem tersebut mengalami masalah dengan pemalsuan, pencurian, dan kecurangan pada sistem absensi membuat banyak media autentikasi berbasis biometrik berkembang. Media autentikasi biometrik yang memiliki tingkat akurasi dan keamanan yang lebih tinggi, salah satunya adalah pengenalan wajah (face recognition).

Untuk membangun sistem pengenalan wajah yang baik agar dapat diterapkan pada sistem identifikasi seseorang, sistem tersebut harus memenuhi beberapa kriteria diantaranya keakuratan pengenalan dan kecepatan pengenalan. Dengan adanya masalah tersebut maka diperlukan suatu analisis terhadap sistem pengenalan wajah, oleh karena itu dilakukan penelitian tentang analisis sistem pengenalan wajah dengan library pada EmguCV.

\section{LANDASAN TEORI}

\section{Sistem Pengenalan Wajah}

Sistem pengenalan wajah adalah aplikasi pengolahan gambar yang dapat mengidentifikasi atau memverifikasi seseorang melalui gambar digital atau frame video yang terkandung dalam suatu gambar tersebut. Sistem pengenalan wajah secara umum dibagi menjadi dua tahap proses yaitu proses deteksi wajah yang merupakan tahap awal dan proses pengenalan wajah. Kedua proses ini memiliki tahapan-tahapan yang hampir sama, perbedaannya terletak pada fiturnya.

Proses deteksi wajah memiliki tahapan-tahapan sebagai berikut, pendeteksian wajah, ekstraksi fitur, dan penyimpanan fitur ke database. Sedangkan pada proses pengenalan wajah, terdiri dari tahapan-tahapan pendeteksian wajah, ekstraksi fitur, pencocokan fitur yang diuji dengan fitur yang disimpan dalam database.

Sistem absensi wajah adalah sistem yang melakukan absensi berdasarkan input gambar hasil capture webcam. Sistem akan melakukan absen dan membandingkan hasil capture wajah dengan database wajah yang telah di- input terlebih dahulu oleh seorang administrator (Admin). 
Proses-proses yang dilakukan dalam sistem absensi ini adalah proses pemasukan data gambar image dengan file wajah hasil capture webcam, proses absensi dengan capture webcam dan hasil capture dibandingkan dengan file wajah pada database dan apabila terjadi kecocokan yang mirip maka sistem absensi bisa dikatakan berhasil.

\section{PERANCANGAN SISTEM}

Pada gambar 1 menunjukan blok diagram sistem pengenalan wajah untuk melakukan pengenalan wajah dari sistem yang digunakan, dimana jalanya sistem dibagi menjadi 2, yaitu tahap pengambilan data dan tahap pengenalan data.

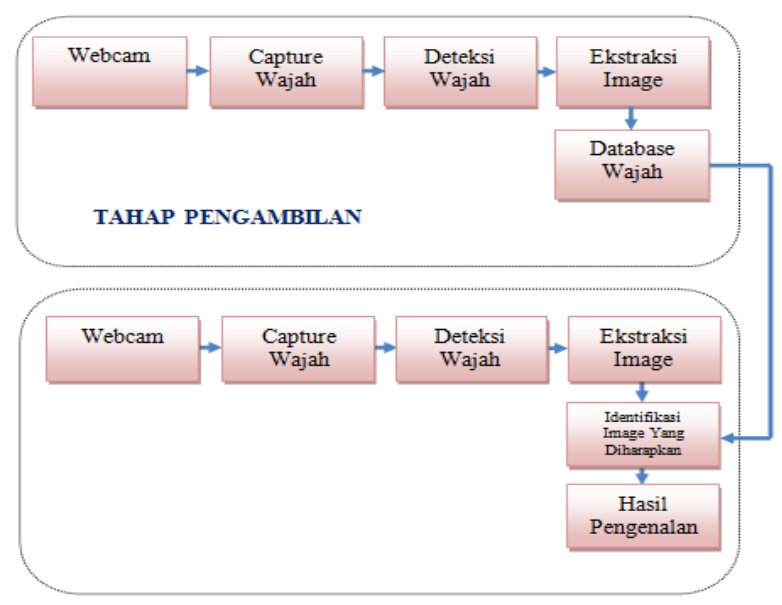

GAMBAR 1. Blok diagram sistem pengenalan wajah.

Jalannya sistem blok tahap pengambilan data adalah sebagai berikut:

- Aktifkan webcam untuk menampilkan gambar yang ditangkap webcam kedalam aplikasi.

- Penangkapan gambar wajah (image capturing) dapat dilakukan secara langsung (real time) menggunakan webcam, setelah terdeteksi adanya gambar wajah pada tampilan window dari webcam.

- Setelah itu dilakukan deteksi objek wajah. Pada proses ini untuk mendeteksi objek wajah saja dan supaya membedakan dengan objek lainnya digunakan metode haar training yaitu Algoritma yang terdapat pada library EmguCV.

- Kemudian langkah yang harus dilakukan selanjutnya adalah penetapan ukuran gambar wajah dimana gambar wajah tersebut saja yang diambil untuk diproses, dan dikonversikan dari RGB image menjadi Grayscale image file.

- Image wajah yang telah dikonversikan disimpan pada folder yang telah ditentukan. Image wajah ini diambil sebagai training dan sebagai nilai pembanding pada proses pengenalan wajah.

Sedangkan untuk proses tahap pengenalan data adalah sebagai berikut:

- Aktifkan webcam untuk menampilkan gambar yang ditangkap webcam kedalam aplikasi.

- Penangkapan citra wajah (image capturing) dapat dilakukan secara langsung (real time) menggunakan webcam, setelah terdeteksi adanya gambar wajah pada tampilan window dari webcam.

- Setelah itu dilakukan deteksi objek wajah. Pada proses ini untuk mendeteksi objek wajah saja dan supaya membedakan dengan objek lainnya digunakan metode haar training yaitu Algoritma yang terdapat pada library EmguCV.

- Kemudian langkah yang harus dilakukan selanjutnya adalah penetapan ukuran gambar wajah dimana gambar wajah tersebut saja yang diambil untuk diproses, dan dikonversikan dari RGB image menjadi Grayscale image file.

- Proses pengenalan wajah dengan membandingkan hasil capture image pada database dengan hasil capture yang diambil secara langsung pada saat tahap pengenalan data. 
- Proses akhir yaitu dengan menampilkan hasil perbandingan dari proses identifikasi dan hasil pengenalan wajah sudah bisa diperoleh.

Capture image yaitu mengambil gambar dengan camera webcam sebelum proses pendeteksian wajah. Pada proses ini aplikasi perangkat lunak menggunakan camera webcam. Dimana resolusi yang digunakan adalah 640 x 480 . Dalam melakukan koneksi dengan webcam, EmguCV telah menyediakan fungsi capture.

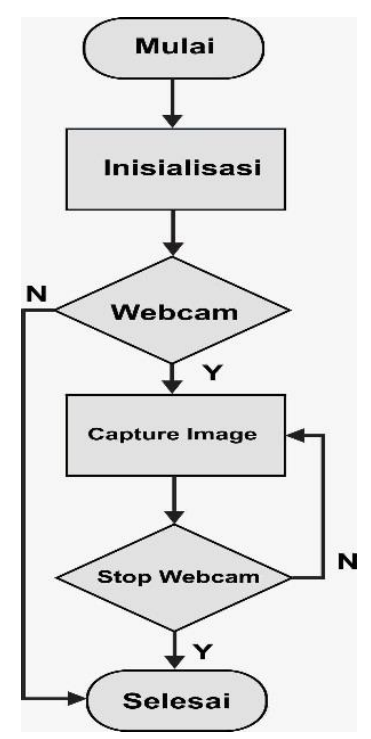

GAMBAR 2. Flowchart capture image.

Metode yang digunakan untuk mendeteksi mata adalah metode Haar Cascade Classifier. Metode ini merupakan metode yang menggunakan statistical model (classifier).

Pada proses ini pendeteksian dilakukan dengan menggunakan algoritma haar classifier yang terdapat pada library EmguCV.

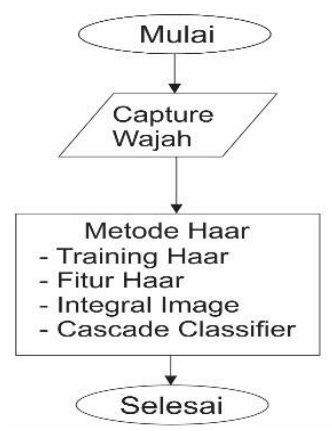

GAMBAR 3. Flowchart deteksi wajah.

Pada Flowchart terdapat istilah Capture Image yaitu proses pengambilan gambar wajah pada webcam yang akan digunakan sebagai data latih. Sedangkan Metode Haar mempunyai tahapantahapan dalam proses pendeteksian wajah, yaitu sebagai berikut Training haar terdiri dari sample positif dan sample negatif. Proses training haar bertujuan untuk memisahkan bagian gambar wajah dengan bagian gambar latar.

Setelah menentukan daerah lokasi dari wajah kemudian dilakukan pencarian obyek wajah yaitu dengan cara mencari fitur-fitur yang memiliki tingkat pembeda yang tinggi. Hal ini dilakukan dengan mengevaluasi setiap fitur terhadap data latih dengan menggunakan nilai dari fitur tersebut. Fitur-fitur ini merupakan gambaran dari wajah manusia yang dikelompokkan berdasarkan sisi yang terang dan sisi yang gelap.

Untuk memilih fitur Haar yang digunakan dan untuk mengubah nilai threshold, Viola dan Jones menggunakan metode machine-learning yang disebut AdaBoost. AdaBoost menggabungkan 
banyak classifier untuk membuat satu classifier. Masing-masing classifier menetapkan suatu bobot, dan gabungan dari bobot inilah yang akan membentuk satu classifier yang kuat. Filter pada masing-masing level dilatih untuk mengklasifikasikan gambar yang sebelumnya telah difilter (Training set merupakan database dari wajah). Selama penggunaannya, jika satu dari filter-filter tersebut gagal, image region/daerah pada gambar diklasifikasikan sebagai "Bukan Wajah". Saat filter berhasil melewatkan image region, image region kemudian masuk pada filter yang selanjutnya. Image region yang telah melalui semua filter akan dianggap sebagai "Wajah".

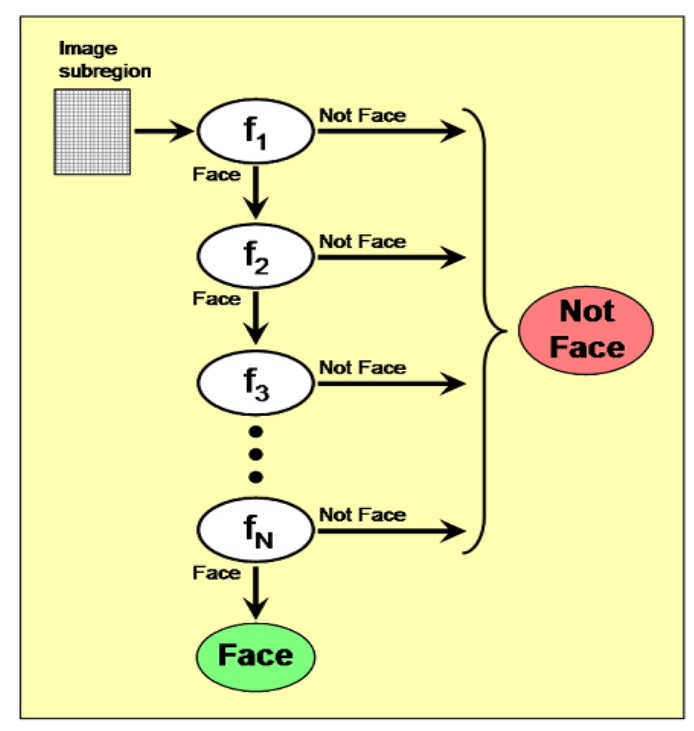

GAMBAR 4. Cascade classifier.

Pada proses ini hasil image yang telah dideteksi akan ditetapkan ukuran gambar wajah dimana gambar wajah tersebut saja yang diambil untuk diproses dan dikonversikan dari $R G B$ image menjadi Grayscale image file. Setelah image dikonversikan image selanjutnya proses crop dan resize image.

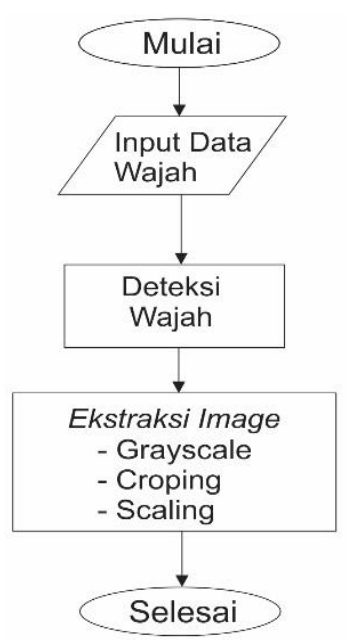

GAMBAR 5. Flowchat ekstraksi image.

Pada proses pengambilan data jumlah data image yang diambil untuk setiap bentuk postur Wajah diambil sebanyak 10 buah, dimana image ini merepresentasikan wajah yang diambil dari berbagai sudut. Dari setiap hasil capture image deteksi objek disimpan dalam format grayscale (*.jpg) berukuran 100x100 pixel. 

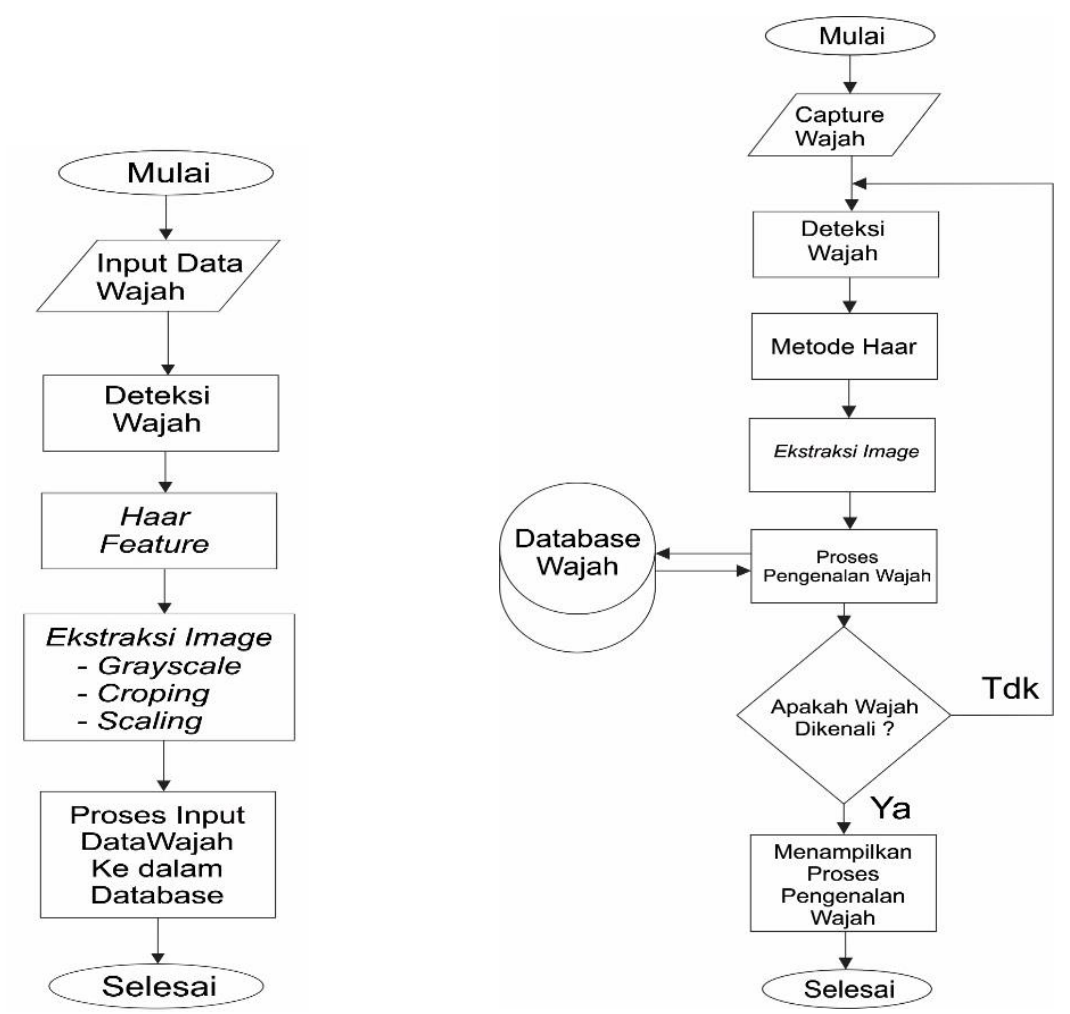

GAMBAR 6. (kiri) Flowchart penyimpanan data; (kanan) gambar flowchart pengenalan wajah.

Dalam library EmguCV terdapat fungsi Haar Cascade Classifier dimana fungsi ini dapat digunakan sebagai tahapan klasifikasi dan pengenalan suatu objek. Data hasil capture image yang tersimpan pada database akan dibandingkan pada proses pengenalan wajah dan dicocokkan dengan data wajah yang tersimpan pada database.

\section{IMPLEMENTASI DAN PENGUJIAN SISTEM}

\section{Implementasi Antarmuka}

Tampilan Login merupakan tampilan yang pertama kali muncul dan berfungsi untuk proses otorisasi administrator. Tampilan Login dapat dilihat seperti ditunjukkan pada gambar 7.

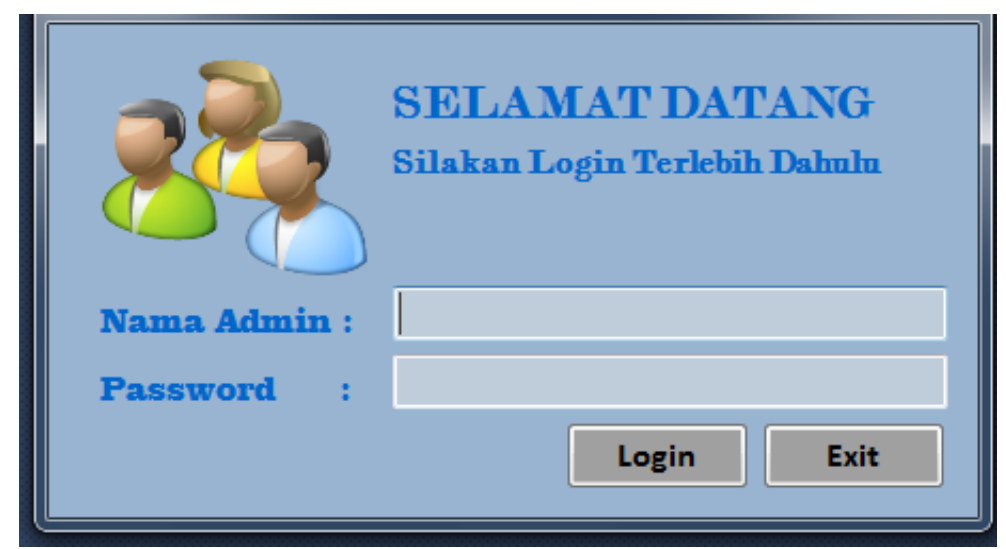

GAMBAR 7. Tampilan form login.

Tampilan Menu Utama merupakan tampilan yang muncul setelah proses otorisasi. Tampilan ini berisi gambar konfigurasi perangkat keras Sistem Absensi Karyawan Berbasis Webcam serta tampilan menu yang berisi beberapa tombol Absensi, data Admin, data Karyawan, Laporan, about serta Exit. Tampilan Menu Utama dapat dilihat pada gambar 8. 


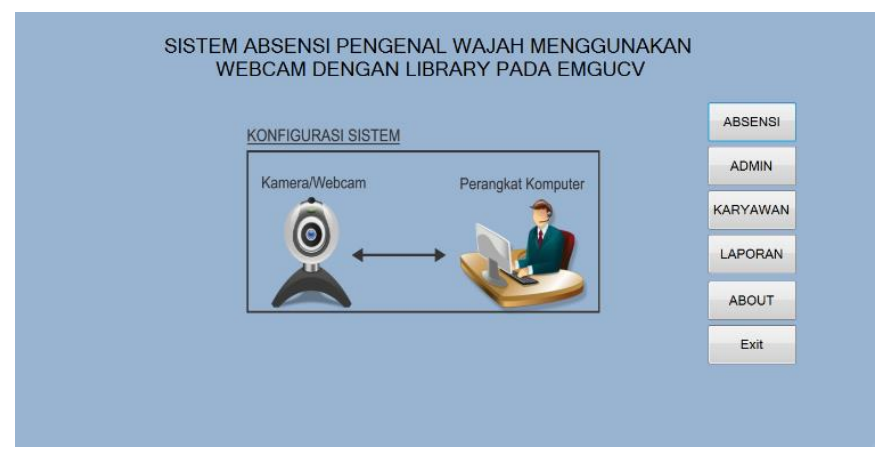

GAMBAR 8. Tampilan form menu utama.

Tampilan Data Admin merupakan tampilan berguna untuk memasukkan data password user yang mengoperasikan sistem. Tampilan data Admin ini dapat dilihat seperti pada gambar 9.

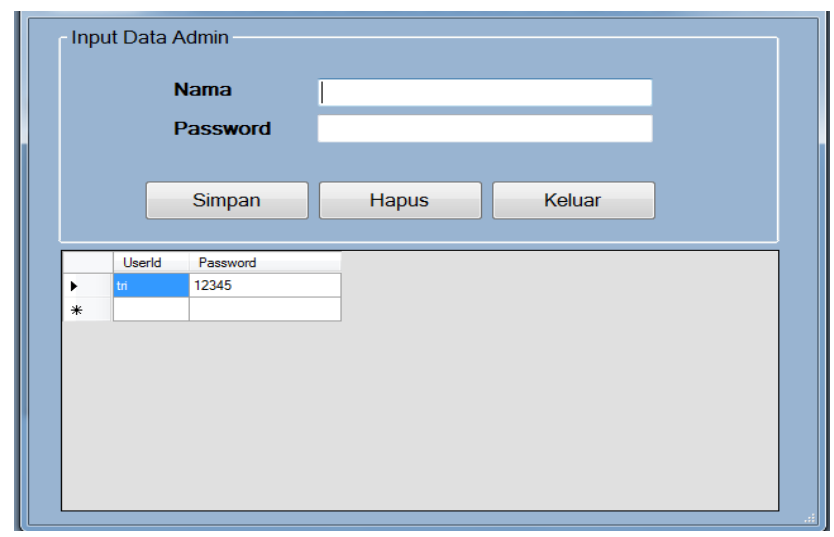

GAMBAR 9. Tampilan form admin.

Tampilan Data Karyawan merupakan tampilan berguna untuk memasukkan data Karyawan yang akan diabsensi pada database. Proses awal sebelum penyimpanan data karyawan yaitu dengan mengenali wajah apakah sudah tersimpan didalam database, jika sudah tersimpan akan menampilkan hasil data pada sebelah kanan berupa data file gambar dan bila belum maka proses selanjutnya dengan menekan tombol Simpan Data Absen. Tampilan awal proses data karyawan dapat dilihat pada Gambar 10.
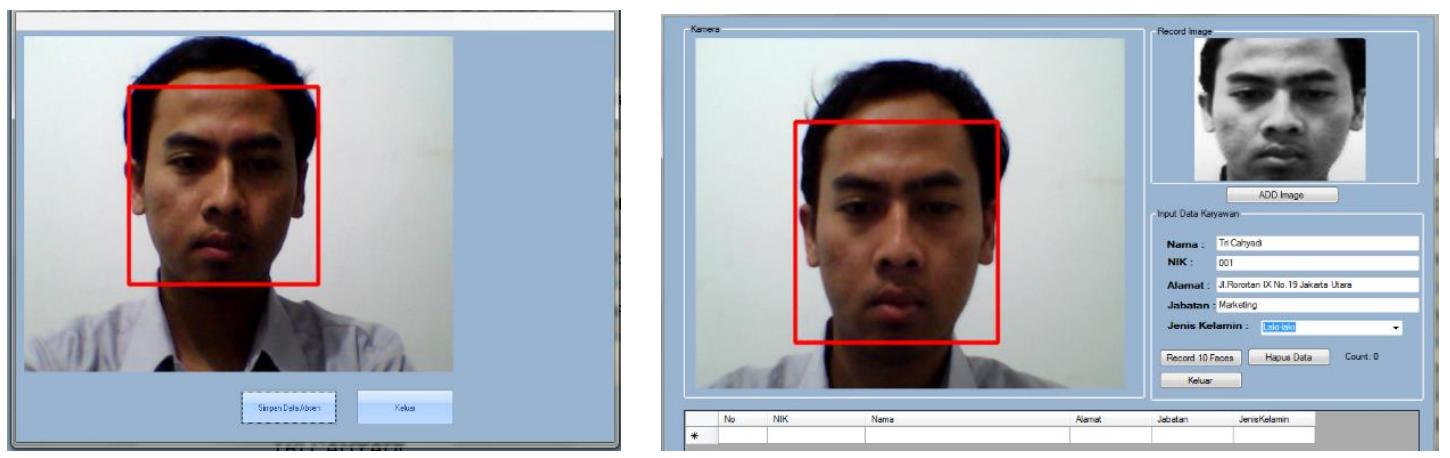

GAMBAR 10. (kiri) Tampilan awal proses data karyawan; (kaman) adalah tampilan input data karyawan.

Proses selanjutnya yaitu penyimpan data dengan cara mengisi semua data pada input data karyawan setelah itu tekan tombol add image untuk proses penyimpanan data wajah dan data karyawan. Tampilan Input data Karyawan dapat dilihat pada gambar 10 bagian kiri.

Pada tampilan data karyawan terdapat pemasukan biodata karyawan dan data wajah karyawan sebagai pembanding yang akan digunakan pada proses absensi. Pada tampilan ini pemasukan foto karyawan dapat dilakukan dengan cara yaitu dengan cara menekan tombol Record 10 Faces atau $A D D$ image capture webcam. 
Tampilan Data Absensi merupakan tampilan berguna untuk memasukkan data absensi karyawan setiap hari berupa hasil capture webcam serta mencocokkan hasil capture dengan data wajah pada database karyawan.

Proses awal sebelum absensi yaitu dengan mengenali wajah apakah sudah tersimpan didalam database, jika sudah tersimpan akan menampilkan hasil data pada sebelah kanan berupa data file gambar dan bila belum maka proses tidak dapat dilanjutkan, selanjutnya dengan menekan tombol Absen.

Setelah proses awal absensi dengan menekan tombol absen proses selanjutnya yaitu proses penyimpanan data absen ke dalam database dengan menekan tombol Absen. Tampilan Laporan Absensi berguna untuk menampilkan data absensi karyawan dan data karyawan yang tersimpan pada database. Pada form laporan absen karyawan ini selain bias menampikan data yang tersimpan pada database bisa pula menampilkan data print ke format PDF dan Microsoft Exel. Tampilan About berfungsi untuk menampilkan data Judul dan Penulis tugas akhir. Pada tampilan ini akan di tampilkan profile dari penulis. Tampilan about dapat dilihat seperti pada gambar 11.

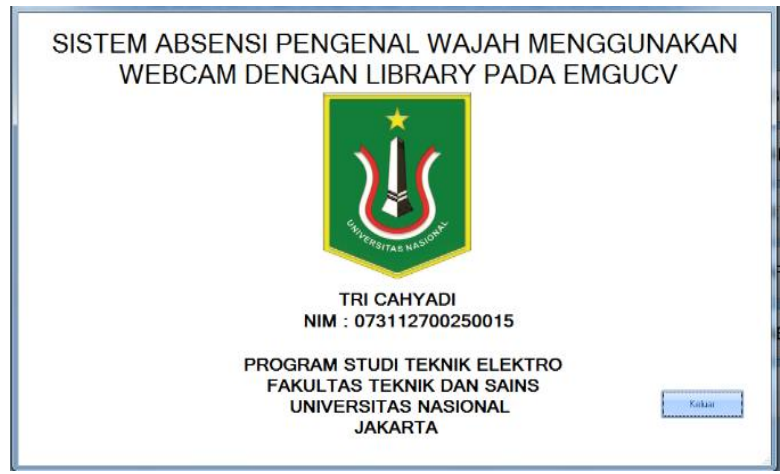

GAMBAR 11. Tampilan about.

\section{Pengujian Software}

Pada uji coba software ini dikhususkan pengujian terhadap form scan karyawan, form karyawan, form scan absensi, form absensi dan form laporan, karena pada form-form tersebut merupakan proses terpenting untuk sistem absensi pengenalan wajah.

Form scan karyawan akan mendeteksi ada tidaknya wajah yang di-input oleh webcam untuk mengambil gambar.
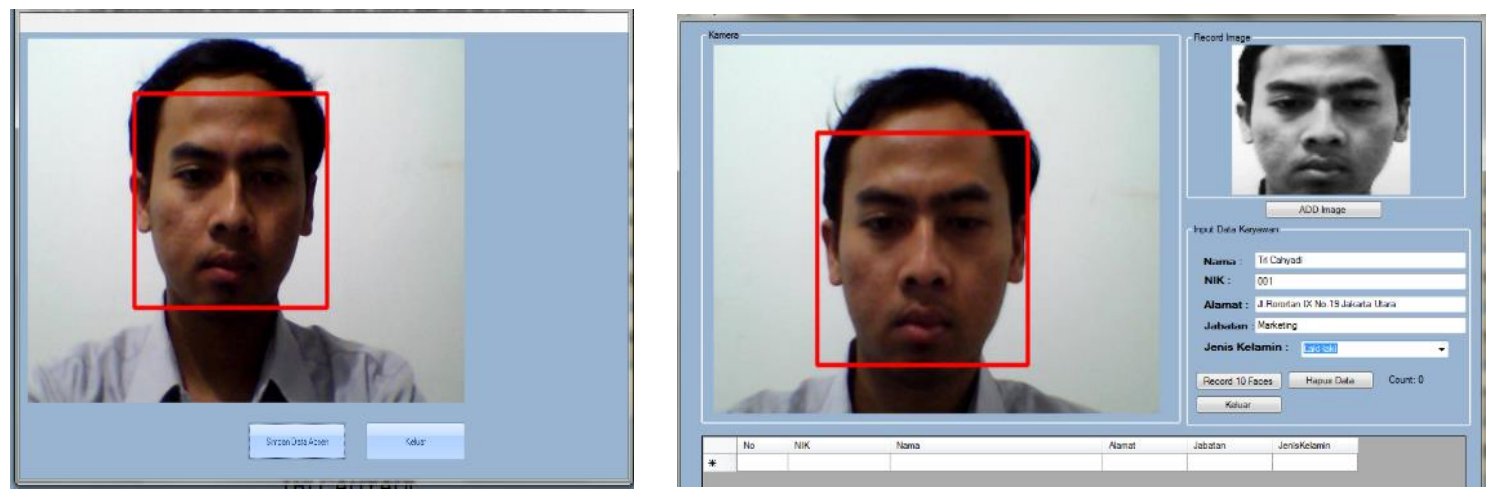

GAMBAR 12. (kiri) Proses deteksi wajah; (kanan) gambar proses input data karyawan

Setelah wajah terdeteksi selanjutnya proses penginputan data karyawan dan penyimpanan data karyawan pada form karyawan yang akan disimpan pada database karyawan. Pada form scan absensi ini akan menampilan proses deteksi wajah yang tersimpan pada database, jika wajah yang di-input oleh webcam terdeteksi maka akan menampilkan hasil berupa data nama dari wajah tersebut dan data wajah yang tersimpan pada database karyawan. 

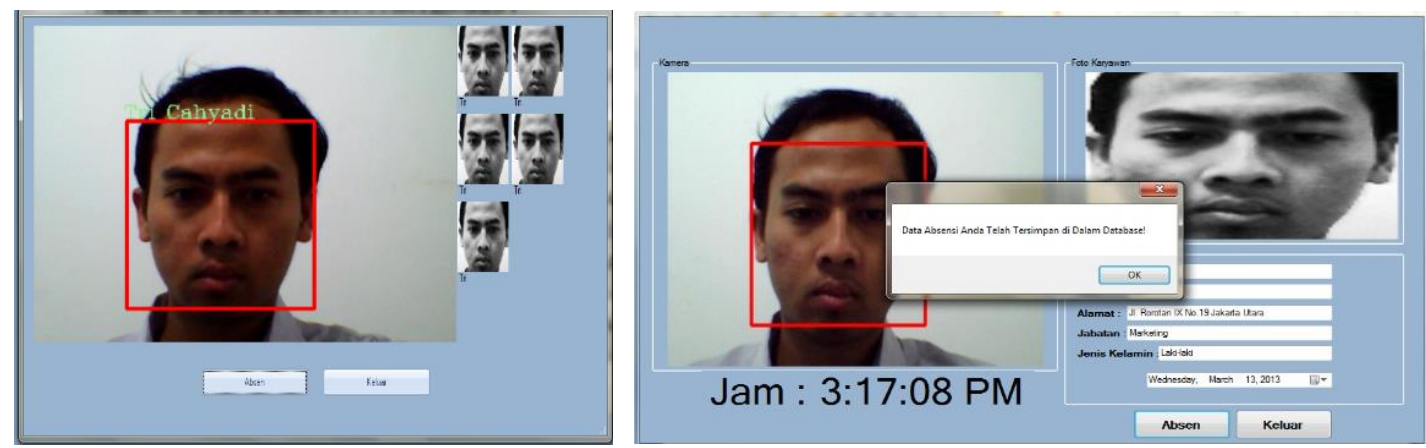

GAMBAR 13. (kiri) Proses hasil deteksi wajah; (kanan) gambar proses input data absensi.

Proses selanjutnya yaitu penyimpanan hasil deteksi wajah pada form absensi pada database absensi. Tahap selanjutnya adalah pengujian form laporan, pengujian ini dilakukan untuk menampilkan hasil penyimpanan data-data pada database karyawan dan database absensi. Fungsi lain form laporan ini bisa print out data dan save data dalam format Microsoft Word, Exel dan $P D F$.

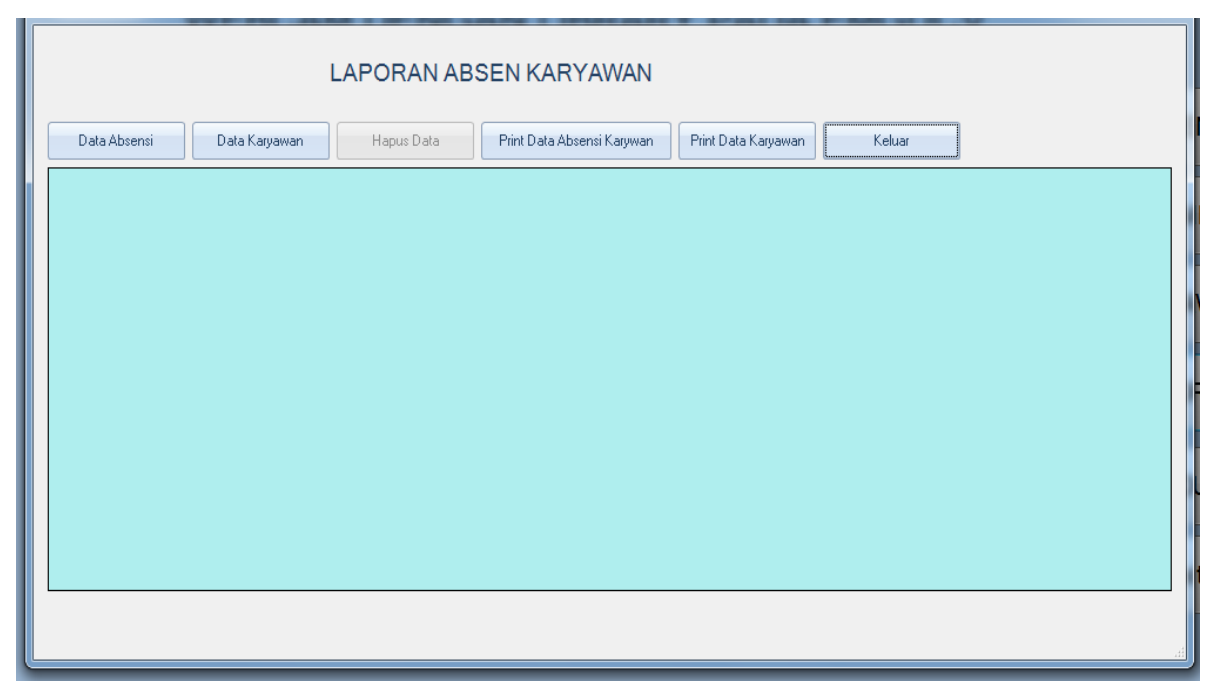

GAMBAR 14. Tampilan form laporan.

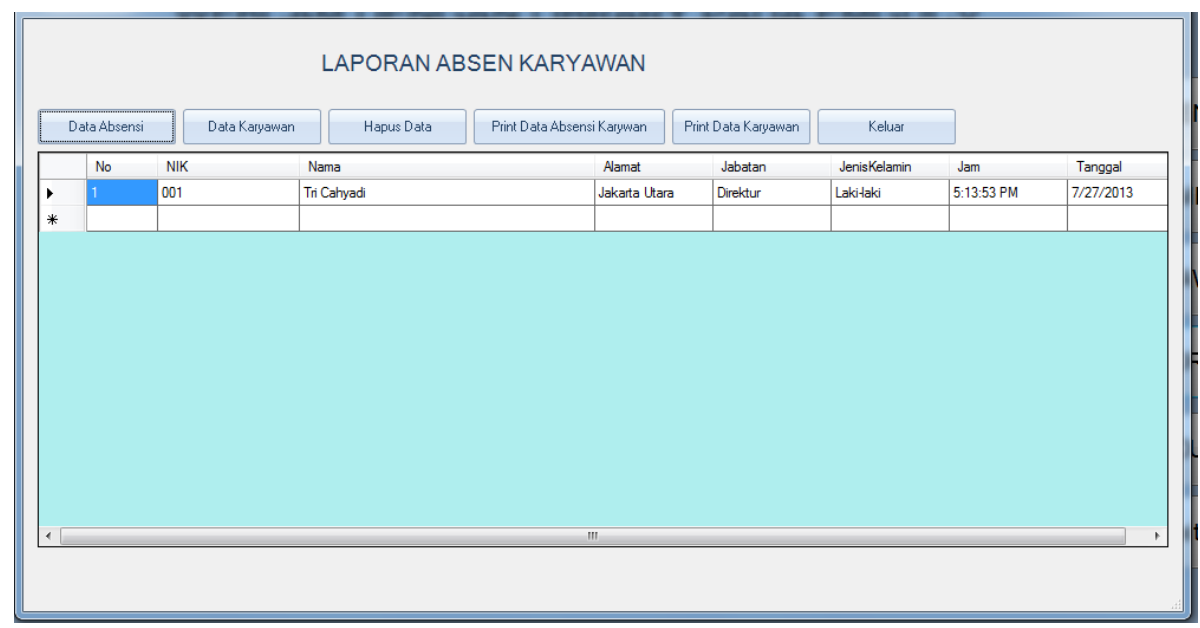

GAMBAR 15. Tampilan database pada data absensi.

\section{Uji Coba Deteksi Wajah}

Pada pengujian ini program yang telah dibuat diujicobakan pada kondisi cahaya yang berbedabeda, yaitu pada kondisi gelap, normal (terang), dan remang-remang. Pengujian ini bertujuan untuk menguji sejauh mana bentuk objek wajah dapat dideteksi. 
TABEL 1. Pengujian Akurasi Deteksi Terhadap Cahaya.

\begin{tabular}{|c|c|c|c|}
\hline Uji ke- & Gelap & Normal & Remang \\
\hline 1 & $\mathrm{X}$ & $\mathrm{V}$ & $\mathrm{V}$ \\
\hline 2 & $\mathrm{X}$ & $\mathrm{V}$ & $\mathrm{V}$ \\
\hline 3 & $\mathrm{X}$ & $\mathrm{V}$ & $\mathrm{X}$ \\
\hline 4 & $\mathrm{X}$ & $\mathrm{V}$ & $\mathrm{X}$ \\
\hline 5 & $\mathrm{X}$ & $\mathrm{V}$ & $\mathrm{V}$ \\
\hline 6 & $\mathrm{X}$ & $\mathrm{V}$ & $\mathrm{X}$ \\
\hline 7 & $\mathrm{X}$ & $\mathrm{V}$ & $\mathrm{V}$ \\
\hline 8 & $\mathrm{X}$ & $\mathrm{V}$ & $\mathrm{V}$ \\
\hline 9 & $\mathrm{X}$ & $\mathrm{V}$ & $\mathrm{V}$ \\
\hline 10 & $\mathrm{X}$ & $\mathrm{V}$ & $\mathrm{V}$ \\
\hline Akurasi Deteksi & $0 \%$ & $100 \%$ & $70 \%$ \\
\hline
\end{tabular}

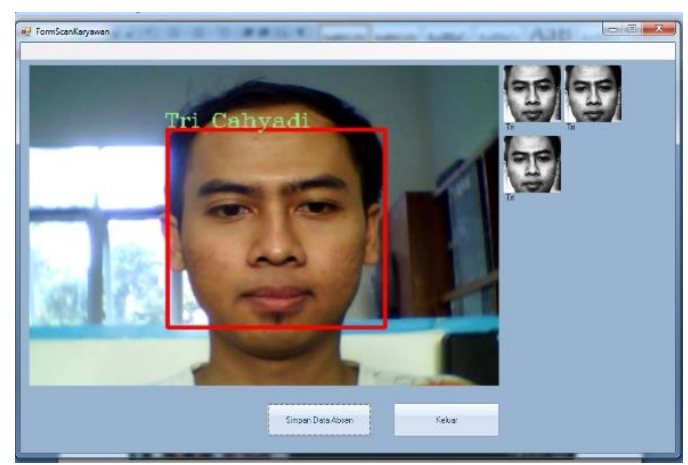

GAMBAR 16. Contoh deteksi dalam kondisi cahaya normal.

Dari hasil percobaan diatas dapat dilihat bahwa faktor pencahayaan sangat mempengaruhi deteksi objek wajah, sehingga dalam hal ini program yang dijalankan harus berada pada kondisi pencahayaan yang cukup (normal).

Pengujian yang dilakukan selanjutnya adalah pengujian akurasi deteksi terhadap jarak. Pengujian jarak ini dengan kondisi cahaya normal. Tujuan pengujian ini adalah mengetahui seberapa jauh program yang telah dibuat dapat mendeteksi wajah dengan variasi jarak yang diujicobakan.

TABEL 2. Pengujian Akurasi Deteksi Terhadap Jarak.

\begin{tabular}{|c|c|c|c|c|c|}
\hline Uji Coba ke- & \multicolumn{5}{|c|}{ Jarak obyek (cm) } \\
\hline & 10 & 30 & 60 & 70 & 90 \\
\hline 1 & $\mathrm{X}$ & $\mathrm{V}$ & $\mathrm{V}$ & $\mathrm{X}$ & $\mathrm{X}$ \\
\hline 2 & $\mathrm{X}$ & $\mathrm{V}$ & $\mathrm{V}$ & $\mathrm{V}$ & $\mathrm{X}$ \\
\hline 3 & $\mathrm{X}$ & $\mathrm{V}$ & $\mathrm{V}$ & $\mathrm{X}$ & $\mathrm{X}$ \\
\hline 4 & $\mathrm{X}$ & $\mathrm{V}$ & $\mathrm{V}$ & $\mathrm{V}$ & $\mathrm{X}$ \\
\hline 5 & $\mathrm{X}$ & $\mathrm{V}$ & $\mathrm{V}$ & $\mathrm{X}$ & $\mathrm{X}$ \\
\hline 6 & $\mathrm{X}$ & $\mathrm{V}$ & $\mathrm{V}$ & $\mathrm{X}$ & $\mathrm{X}$ \\
\hline 7 & $\mathrm{X}$ & $\mathrm{V}$ & $\mathrm{V}$ & $\mathrm{V}$ & $\mathrm{X}$ \\
\hline 8 & $\mathrm{X}$ & $\mathrm{V}$ & $\mathrm{V}$ & $\mathrm{X}$ & $\mathrm{X}$ \\
\hline 9 & $\mathrm{X}$ & $\mathrm{V}$ & $\mathrm{V}$ & $\mathrm{V}$ & $\mathrm{X}$ \\
\hline 10 & $\mathrm{X}$ & $\mathrm{V}$ & $\mathrm{V}$ & $\mathrm{X}$ & $\mathrm{X}$ \\
\hline Akurasi Deteksi & $0 \%$ & $100 \%$ & $100 \%$ & $40 \%$ & $0 \%$ \\
\hline
\end{tabular}


Dari hasil percobaan diatas dapat dikatakan bahwa faktor jarak antara alat (webcam) dengan objek wajah mempengaruhi dalam pendeteksian. Hal ini dikarenakan image data training yang disimpan pada kondisi dan jarak tertentu. Untuk jarak efektif pendeteksian dilakukan pada jarak $30 \mathrm{~s} / \mathrm{d} 50$ $\mathrm{cm}$. Kecepatan user saat pergerakan penangkapan objek wajah sangat berpengaruh terhadap baik buruknya deteksi sehingga perlu dilakukan terlebih dahulu agar menghasilkan kesimpulan kecepatan dalam pendeteksian objek wajah.

TABEL 3. Pengujian Terhadap Kecepatan Gerakan.

\begin{tabular}{|c|c|c|c|}
\hline Uji Coba ke- & Diam & Sedang & Cepat \\
\hline 1 & $\mathrm{~V}$ & $\mathrm{~V}$ & $\mathrm{X}$ \\
\hline 2 & $\mathrm{~V}$ & $\mathrm{~V}$ & $\mathrm{X}$ \\
\hline 3 & $\mathrm{~V}$ & $\mathrm{~V}$ & $\mathrm{~V}$ \\
\hline 4 & $\mathrm{~V}$ & $\mathrm{~V}$ & $\mathrm{X}$ \\
\hline 5 & $\mathrm{~V}$ & $\mathrm{~V}$ & $\mathrm{X}$ \\
\hline 6 & $\mathrm{~V}$ & $\mathrm{~V}$ & $\mathrm{~V}$ \\
\hline 7 & $\mathrm{~V}$ & $\mathrm{~V}$ & $\mathrm{X}$ \\
\hline 8 & $\mathrm{~V}$ & $\mathrm{~V}$ & $\mathrm{X}$ \\
\hline 9 & $\mathrm{~V}$ & $\mathrm{X}$ & $\mathrm{V}$ \\
\hline 10 & $\mathrm{~V}$ & $\mathrm{~V}$ & $\mathrm{~V}$ \\
\hline Akurasi Deteksi & $100 \%$ & $90 \%$ & $40 \%$ \\
\hline
\end{tabular}

Dari tabel 3 Terlihat bahwa semakin cepat user mengerakan wajah, maka tingkat keberhasilan deteksi semakin kecil.

\section{Pengujian Terhadap Kemiringan Posisi Wajah}

Dari gambar terlihat bahwa pada saat sudut $0^{0}$ sampai $10^{\circ}$ objek dapat dikenali, pada saat sudut $30^{\circ}$ objek tidak dapat dikenali lagi.

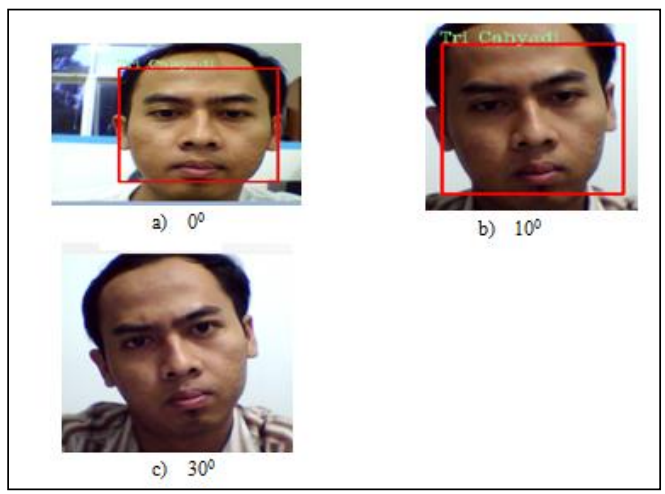

GAMBAR 17. Pengujian Terhadap Kemiringan a. $0^{0}$, b. $10^{\circ}$, c. $30^{\circ}$.

Juga dilakukan pengujian pengenalan deteksi wajah. Pengujian proses pengenalan wajah akan dilakukan dengan membandingkan beberapa gambar yang sudah tersimpan didalam database. Pada pengujian ini terdiri dari 3 wajah yang terdiri dari 10 sampel pada masing-masing wajah.

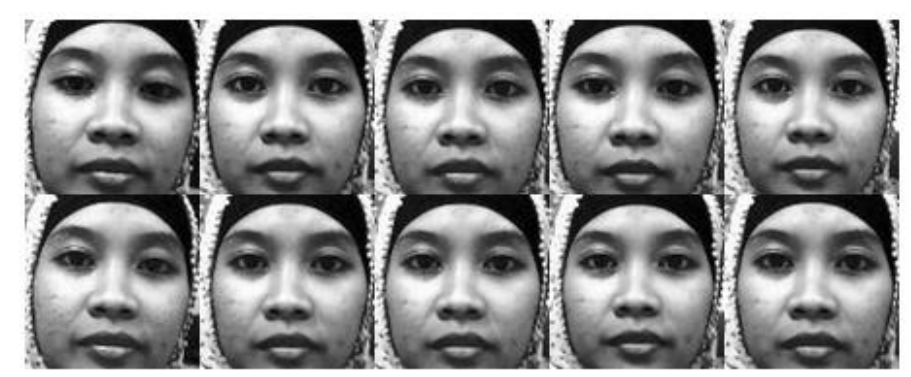

GAMBAR 18. 10 Sample wajah Resty. 


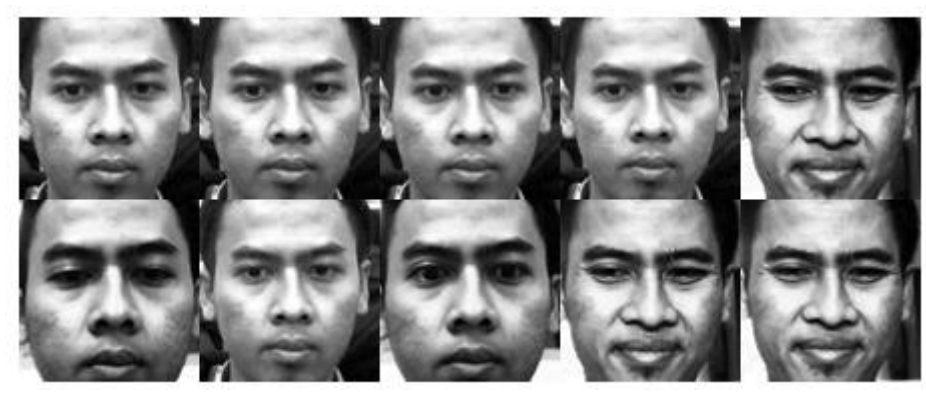

GAMBAR 19. 10 Sampel wajah Tri Cahyadi.

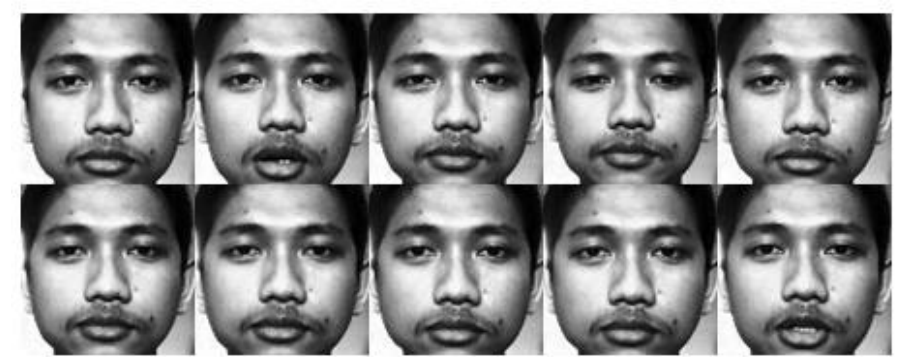

GAMBAR 20. 10 Sampel wajah Abdul Aziz.

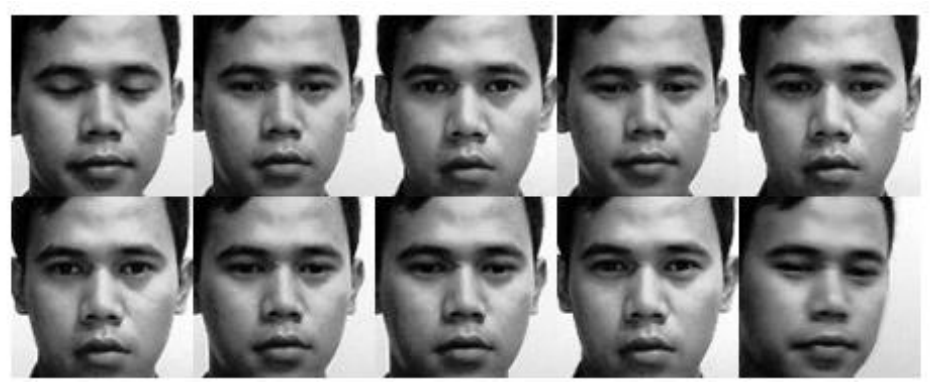

GAMBAR 21. 10 Sampel wajah Puri.

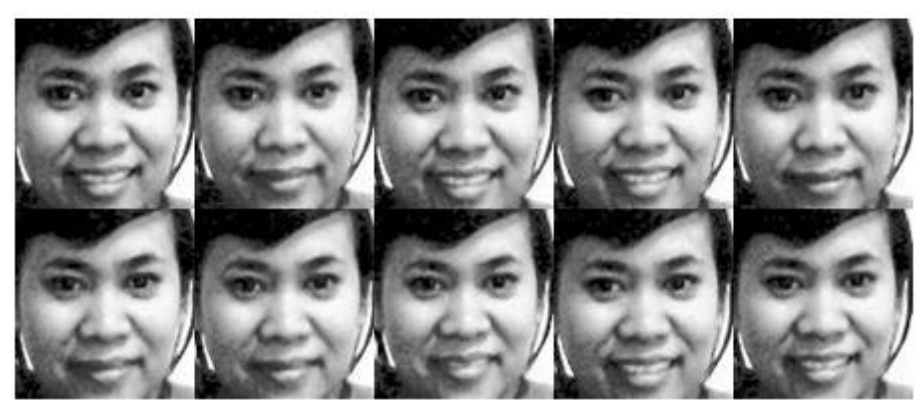

GAMBAR 22. 10 Sampel wajah Winda.

TABEL 4. Pengujian Pengenalan Deteksi Wajah 10 sample Uji

\begin{tabular}{|c|c|}
\hline $\begin{array}{c}\text { Nama Sample Uji } \\
\text { Wajah }\end{array}$ & $\begin{array}{c}\text { Nama Sample } \\
\text { Pengenalan } \\
\text { Wajah }\end{array}$ \\
\hline Tri Cahyadi & Tri Cahyadi \\
\hline Abdul Aziz & Resty \\
\hline Resty & Resty \\
\hline Winda & Winda \\
\hline Puri & Puri \\
\hline
\end{tabular}

Keakuratan $=($ Jumlah Hasil Benar $/$ Jumlah Pengujian $) \times 100 \%$ Keakuratan $=(4 / 5) \times 100 \%=80 \%$ 
TABEL 5. Pengujian Pengenalan Deteksi Wajah 100 sample Uji

\begin{tabular}{|c|c|}
\hline $\begin{array}{c}\text { Nama Sample Uji } \\
\text { Wajah }\end{array}$ & $\begin{array}{c}\text { Nama Sample } \\
\text { Pengenalan Wajah }\end{array}$ \\
\hline Tri Cahyadi & Tri Cahyadi \\
\hline Abdul Aziz & Abdul Aziz \\
\hline Resty & Resty \\
\hline Winda & Winda \\
\hline Puri & Puri \\
\hline
\end{tabular}

Keakuratan $=($ Jumlah Hasil Benar $/$ Jumlah Pengujian $) \times 100 \%$

Keakuratan $=(5 / 5) \times 100 \%=100 \%$

Pengujian pengenalan wajah ini pada kondisi cahaya normal. Dari hasil pengujian bahwa proses pendeteksian 10 sample uji masih belum terdeteksi dengan baik, maka dibutuhkan banyak sample uji untuk hasil deteksi agar mudah dikenali sesuai dengan sample pengenalan.

\section{KESIMPULAN}

Dari hasil perancangan sampai dengan pengujian didapatkan kesimpulan tinggi rendahnya unsur pencahayaan yang berada di sekitar obyek sangat mempengaruhi proses pendeteksian. Jarak antara wajah dengan webcam sangat berpengaruh dalam proses pendeteksian wajah. Jarak ideal pendeteksian wajah yaitu $30-60 \mathrm{~cm}$. Pergerakan objek wajah sangat berpengaruh dalam proses pendeteksian wajah. Gerakan yang terlalu cepat menghasilkan deteksi yang sangat lemah. Proses pengenalan wajah dibutuhkan banyak sample untuk dapat mengenali wajah dengan baik.

\section{DAFTAR PUSTAKA}

[1] Gonzalez, C, Rafael., and Woods, E, Richard., "Digital Image Processing $3^{\text {rd }}$, New Jersey, USA Pearson Prentice Hall, 2008.

[2] Putra Darma., "Pengolahan Citra Digital", Penerbit Andi, Yogyakarta, 2009

[3] Mohamad Aditya Rahman, \& Ir. Sigit Wasista, M. Kom., "Sistem Pengenalan Wajah Menggunakan Webcam Untuk Absensi Dengan Metode Template Maching", JurusanTeknik Elektronika, Politeknik Elektronika Negeri Surabaya, 2011.

[4] Sandra Agustyan Putra, Sigit Wasista, \& Bima Sena Bayu D.," Sistem Absensi Mahasiswa Secara Visual Menggunakan Webcam Dengan Dynamic Times Warping", Politeknik Elektronika Negeri Surabaya - Institut Teknologi Sepuluh Nopember (ITS), Surabaya, 2011.

[5] Endah Sudarmilah., "Sistem Pelacakan Wajah Metode Haar", Universitas Muhammadiyah Surakarta, 2010.

[6] Andi., "Pemograman Visual Basic 6.0", WahanaKomputer, Semarang, 2000.

[7] Feri, "Grayscale", http://www.total.or.id/info.php?kk=Grayscale, 19.06.2013.

[8] Risqi, "Pengertian EmguCV", http://students.netindonesia.net/blogs/risqi/archive/2011/10/05/emgu-cv-part-1, 19.06.2013

[9] Moeza, "Pengertian Webcam", http://m0eza-9raphic.blogspot.com/2009/03/fungsi-danbagian-bagian-webcam, 22.06.2013 